\title{
Tamsulosin-induced severe hypotension during general anesthesia: a case report
}

\author{
Dileep Kumar*, Fauzia Anis Khan
}

\begin{abstract}
Introduction: Tamsulosin, a selective $\alpha_{1}$-adrenergic receptor $\left(\alpha_{1}\right.$-AR) antagonist, is a widely prescribed first-line agent for benign prostatic hypertrophy (BPH). Its interaction with anesthetic agents has not been described.

Case presentation: We report the case of 54-year-old Asian man undergoing elective left thyroid lobectomy. The only medication the patient was taking was tamsulosin $0.4 \mathrm{mg}$ for the past year for BPH. He developed persistent hypotension during the maintenance phase of anesthesia while receiving oxygen, nitrous oxide and $1 \%$ isoflurane. The hypotension could have been attributable to a possible interaction between inhalational anesthetic and tamsulosin.
\end{abstract}

Conclusion: Vigilance for unexpected hypotension is important in surgical patients who are treated with selective $\alpha_{1}$-AR blockers. If hypotension occurs, vasopressors that act directly on adrenergic receptors could be more effective.

\section{Introduction}

Tamsulosin (benzenesulfonamide) is a uroselective $\alpha_{1 \mathrm{~A}^{-}}$ adrenergic receptor $\left(\alpha_{1 \mathrm{~A}}-\mathrm{AR}\right)$ antagonist primarily used for patients with benign prostatic hyperplasia $(\mathrm{BPH})$ presenting with lower urinary tract symptoms [1]. The recommended dose is $0.4 \mathrm{mg}$ or $0.8 \mathrm{mg}$ with a half-life of nine to 15 hours. It is extensively metabolized by the liver.

Currently, $\alpha_{1}$-adrenergic receptor $\left(\alpha_{1}\right.$-AR) antagonists are commonly prescribed by physicians as first-line agents to treat $\mathrm{BPH}$, a common condition of aging men. $\alpha_{1}$-AR antagonists exert their effects by blocking $\alpha_{1}$-ARmediated contraction of the prostatic smooth muscle cells and bladder neck [2]. There are three $\alpha_{1}$-AR subtypes: $\alpha_{1 \mathrm{~A}}, \alpha_{1 \mathrm{~B}}$ and $\alpha_{1 \mathrm{D}}$. Terazosin, doxazosin and alfuzosin are $\alpha_{1}$-AR antagonists that show equal affinity for all $\alpha_{1}$-AR subtypes [3]. Tamsulosin does not interfere with blood pressure control and has a low potential to cause vasodilation [4]. It is selective for $\alpha_{1 \mathrm{~A}}$-and $\alpha_{1 \mathrm{D}}-\mathrm{AR}$ subtypes but has less affinity for the $\alpha_{1 \mathrm{~B}}$ subtype.

\section{Case presentation}

A 54-year-old, 80-kg Asian man was scheduled for left thyroid lobectomy for a thyroid nodule. He was

\footnotetext{
* Correspondence: dkhiloi@yahoo.com

Department of Anesthesia, Aga Khan University PO Box 3500, Stadium Road,
} Karachi, Pakistan clinically euthyroid with normal thyroid function test results. The patient's medical history was insignificant except for BPH. His New York Heart Association classification was class I. For BPH, he was being treated with tamsulosin $0.4 \mathrm{mg}$ at night for one year. He was a smoker and had been smoking approximately 20 cigarettes a day for the past 24 years. He had no known history of allergy to any drug. He consented to general anesthesia for thyroid lobectomy.

Before induction of anesthesia, the patient's recorded blood pressure (BP) was $137 / 88 \mathrm{~mm} \mathrm{Hg}$, heart rate was $72 \mathrm{bpm}$, and temperature was $36.5^{\circ} \mathrm{C}$. Cefazolin $1 \mathrm{~g}$ was administered intravenously (IV) in the operating room without any adverse effects. After placement of routine monitors and preoxygenation, general anesthesia was induced with sodium thiopentone $5 \mathrm{mg} / \mathrm{kg}$, pethidine $1 \mathrm{mg} / \mathrm{kg}$ and atracurium $0.5 \mathrm{mg} / \mathrm{kg}$, and the patient's trachea was intubated with a reinforced endotracheal tube without any difficulty. The lungs were ventilated with a controlled mode of ventilation with $\mathrm{O}_{2} / \mathrm{N}_{2} \mathrm{O}$ and $1 \%$ isoflurane. The two $\mathrm{BP}$ readings taken after induction were $110 / 70$ and $100 / 64 \mathrm{~mm} \mathrm{Hg}$. After laryngoscopy, the patient's maximum BP reading was $162 / 96$ $\mathrm{mm} \mathrm{Hg}$, and his heart rate was 104 beats $/ \mathrm{min}$. Within 10 minutes, the patient's BP decreased to $75 / 45 \mathrm{~mm} \mathrm{Hg}$ despite a rapid infusion of $1 \mathrm{~L}$ of lactated Ringer's 
solution. His heart rate remained at $70 \mathrm{bpm}$, and his oxygen saturation was between $98 \%$ and $99 \%$. End-tidal carbon dioxide remained between 33 and $36 \mathrm{~mm} \mathrm{Hg}$, with a respiratory rate of 10 breaths/min. Ephedrine 30 $\mathrm{mg}$ in divided IV doses only transiently improved the hypotension (BP to $85 / 40 \mathrm{~mm} \mathrm{Hg}$ ), and frequent phenylephrine boluses (100 $\mu \mathrm{g} /$ bolus) were required to maintain systolic BP above $90 \mathrm{~mm} \mathrm{Hg}$. The patient's skin was warm but not diaphoretic. Skin erythema, urticaria, bronchospasm, facial edema and other features of a potential anaphylaxis or anaphylactoid reaction were absent. No ischemic changes were observed on a threelead electrocardiogram (ECG). General anesthesia was maintained with $\mathrm{O}_{2} / \mathrm{N}_{2} \mathrm{O}$ and isoflurane minimum alveolar concentration (MAC) of $0.8 \%$. At this point, the differential diagnosis of hypotension was primarily directed to deep anesthesia or hypovolemia. While these were being addressed, the surgeon was allowed to proceed. There was continuing hypotension requiring phenylephrine. At the time of surgical incision, the patient moved slightly in response to surgical stimulation. The total duration of surgery was 180 minutes (three hours), and the total estimated blood loss was $70 \mathrm{~mL}$. A total of $1200 \mu \mathrm{g}$ of phenylephrine was required to maintain the systolic a BP above $90 \mathrm{~mm} \mathrm{Hg}$ throughout surgery.

At the end of surgery, isoflurane was turned off, and the patient's BP increased to $110 / 70 \mathrm{~mm} \mathrm{Hg}$ with a heart rate of $75 \mathrm{bpm}$. The patient completely recovered from neuromuscular blockade after administration of $0.2 \mathrm{mg}$ of glycopyrrolate and $2.5 \mathrm{mg}$ of neostigmine. The patient's trachea was then extubated, and he was shifted to the postanesthesia care unit. He remained in the recovery room for two hours and remained hemodynamically stable with BP in the range of $120 / 75$ to 140/80 $\mathrm{mm} \mathrm{Hg}$ and heart rate between 70 and $76 \mathrm{bpm}$.

\section{Discussion}

$\mathrm{BPH}$ is common among older men, with approximately $25 \%$ of men being affected after 40 years of age [5]. Histologic evidence of the disease is noted in $8 \%$ of men in their $30 \mathrm{~s}$, and the prevalence rapidly increases to more than $70 \%$ after the age 60 years [6].

All $\alpha 1$-adrenoceptor antagonists have a similar efficacy in improving symptoms and urinary flow. Many of these agents were initially developed and approved for the treatment of patients with hypertension until the development of tamsulosin. Tamsulosin is a more selective $\alpha_{1 \mathrm{~A}}$ subtype antagonist, which maintains the $\alpha$-antagonist effect on the prostatic capsule and bladder neck but has less of an effect on the vascular system and BP. Tamsulosin is not indicated in the treatment of patients with hypertension.

A meta-analysis related to the vascular-related safety profile of $\alpha_{1}$ antagonists was carried out by Nickel et al [7].
They concluded that patients administered alfuzosin, terazosin and doxazosin showed a statistically significant increased risk of developing vascular-related events (dizziness, hypotension or syncope) compared with those taking placebo. Tamsulosin showed only a numerical increase that was not statistically significant.

A MEDLINE search from 1997 to the present revealed no report of any adverse hemodynamic consequences of tamsulosin interaction under anesthesia. Tamsulosin drug interactions have been studied in humans; the use of tamsulosin with nifedipine, enalapril, atenolol, furosemide or digoxin does not require dosage modification when tamsulosin is initiated concomitantly with these agents $[8,9]$. Tamsulosin is contraindicated with other $\alpha 1$ antagonist and verapamil, which has $\alpha_{1}$-adrenoceptor antagonist effects in therapeutic doses [10]. It is contraindicated in patients with orthostatic hypotension.

This case may illustrate a drug interaction between tamsulosin and inhalational anesthetic agents. Isoflurane is the most likely anesthetic drug to have interacted because the phenylephrine requirement lasted until the end of the case, and the hypotension resolved when isoflurane was stopped. The hypotension in this patient may have been caused by chronic use of tamsulosin. Isoflurane is a known vasodilator and may have synergetic effect with tamsulosin. This may explain why ephedrine was less effective than phenylephrine in counteracting hypotension. Whereas phenylephrine is a pure $\alpha_{1}$-AR agonist, ephedrine has both central and peripheral effects. In the clinical doses administered, its peripheral effects may be less than those of phenylephrine. Ephedrine was administered initially because the differential diagnosis considered at that time was either excessive depth of anesthesia or hypovolemia. When a synergetic effect was suspected, phenylephrine was used instead. The point that negated vasodilation caused by an inappropriate depth of anesthesia was that the patient was receiving less than 1 MAC of isoflurane, and he moved in response to surgical stimulation at the time of incision. Hypovolemia was ruled out when the BP did not rise after administration of $1 \mathrm{~L}$ of crystalloid.

The degree of hypotension was exceptional compared with the concentration of anesthetic agent used. The other differential diagnosis for this vasodilated hypotensive state included anaphylaxis and myocardial ischemia. Because the patient did not have any other features of anaphylaxis and had a subsequent negative ECG result for ischemia, these alternative diagnoses were rejected. Other anesthetic drugs used in this patient were thiopentone, pethidine and atracurium. Pethidine and atracurium can both cause histamine release, but no additional clinical signs of histamine release were apparent in this patient. The dramatic increase in BP when isoflurane was turned off goes in favor of some kind of 
interaction, although the possibility of genetic sensitivity to isoflurane cannot be ruled out completely.

As a result of the recent increase in prescriptions of tamsulosin for aging men with BPH, hypotension under anesthesia associated with this drug may occur. To remove tamsulosin from the circulation would require days of abstinence because tamsulosin has a long halflife of nine to 15 hours.

\section{Conclusion}

This case reports hypotension in a patient on tamsulosin under general anesthesia with $\mathrm{N}_{2} \mathrm{O} / \mathrm{O}_{2}$, atracurium and isoflurane anesthesia. Other factors may have contributed to the decreased BP, and tamsulosin cannot be implicated definitively. This case nevertheless demonstrates the importance of vigilance for unexpected hypotension in patients taking tamsulosin. If hypotension does develop in these patients, a direct-acting vasopressor such as phenylephrine should be used.

\section{Consent}

Written informed consent was obtained from the patient for publication of this case report. A copy of the written consent is available for review by the Editor-in-Chief of this journal.

\section{Abbreviations}

$\alpha_{1}$-AR ANTAGONIST: $\alpha_{1}$-adrenergic receptor antagonist; $\mathrm{BPH}$ : benign prostatic hypertrophy; ECG: electrocardiogram; MAC: minimum alveolar concentration; $\mathrm{N}_{2} \mathrm{O}$ : nitrous oxide.

\section{Authors' contributions}

Both authors contributed to the clinical management of the case. The initial draft of the case report was written by DK, and repeated revisions were done by both DK and FAK. Both authors read and approved the final version of the manuscript.

\section{Competing interests}

The authors declare that they have no competing interests.

Received: 5 January 2010 Accepted: 17 November 2010

Published: 17 November 2010

\section{References}

1. Wilde Ml, McTavish D: Tamsulosin-a review of its pharmacological properties and therapeutic potential in the management of benign prostatic hyperplasia. Drugs 1996, 52:883-896.

2. Lepor H, Lowe FC: Evaluation and nonsurgical management of benign prostatic hyperplasia. In Campbell's Urology.. 8 edition. Edited by: Walsh PC, Retik AB, Vaughan ED, Wein AJ. Philadelphia: WB Saunders; 2002:1337-1378.

3. Foglar R, Shibata K, Horie K, Hirasawa A, Tsujimoto G: Use of recombinant $a_{1}$-adrenoreceptors to characterize subtype selectivity of drugs for the treatment of prostatic hypertrophy. Eur J Pharmacol 1995, 288:201-207.

4. Beduschi MC, Beduschi R, Oesterling JE: Alpha-blockade therapy for benign prostatic hyperplasia: from a nonselective to a more selective ${ }_{1 A}{ }_{1 A}$-adrenergic antagonist. Urology 1998, 51:861-872.

5. Chute CG, Pander LA, Girman CJ, et al: The prevalence of prostatism: a population-based survey of urinary symptoms. J Urol 1993, 150:85-89.

6. Berry SJ, Coffey DS, Walsh PC, Ewing LL: The development of human benign prostatic hyperplasia with age. J Urol 1984, 132:474-479.
7. Nickel JC, Sander S, Moon TD: A meta-analysis of the vascular-related safety profile and efficacy of a-adrenergic blockers for symptoms related to benign prostatic hyperplasia. Int J Clin Pract 2008, 62:1547-1559.

8. Lowe FC: Coadministration of tamsulosin and three antihypertensive agents in patients with benign prostatic hyperplasia: pharmacodynamic effect. Clin Ther 1997, 19:730-742.

9. Michel MC, Bressel HU, Goepel M, Rubben H: A 6-month large-scale study into the safety of tamsulosin. Br J Clin Pharmacol 2001, 51:609-614.

10. de Mey C, Michel MC, McEwen J, Moreland T: A double-blind comparison of terazosin and tamsulosin on their differential effects on ambulatory blood pressure and nocturnal orthostatic stress testing. Eur Urol 1998, 33:481-488.

doi:10.1186/1752-1947-4-365

Cite this article as: Kumar and Khan: Tamsulosin-induced severe hypotension during general anesthesia: a case report. Journal of Medical Case Reports 2010 4:365.

\section{Submit your next manuscript to BioMed Central and take full advantage of:}

- Convenient online submission

- Thorough peer review

- No space constraints or color figure charges

- Immediate publication on acceptance

- Inclusion in PubMed, CAS, Scopus and Google Scholar

- Research which is freely available for redistribution 